
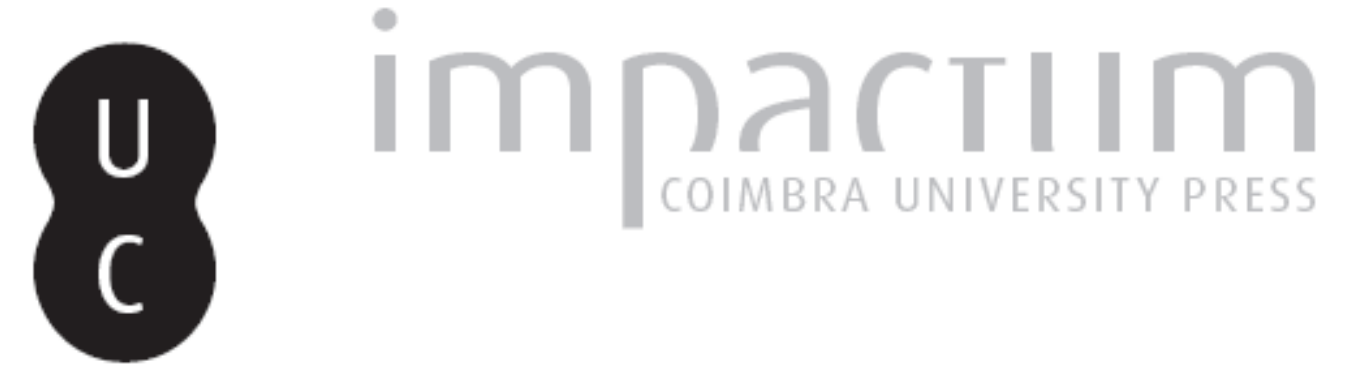

\title{
O litoral brasileiro: a valorização do espaço e os riscos socioambientais
}

\author{
Autor(es): $\quad$ Vitte, Antonio Carlos
}

Publicado por: Associação Portuguesa de Riscos, Prevenção e Segurança

URL persistente:

URI:http://hdl.handle.net/10316.2/40072

DOI:

DOI:https://doi.org/10.14195/1647-7723_10_4

Accessed : $\quad$ 26-Apr-2023 16:11:35

A navegação consulta e descarregamento dos títulos inseridos nas Bibliotecas Digitais UC Digitalis, UC Pombalina e UC Impactum, pressupõem a aceitação plena e sem reservas dos Termos e Condições de Uso destas Bibliotecas Digitais, disponíveis em https://digitalis.uc.pt/pt-pt/termos.

Conforme exposto nos referidos Termos e Condições de Uso, o descarregamento de títulos de acesso restrito requer uma licença válida de autorização devendo o utilizador aceder ao(s) documento(s) a partir de um endereço de IP da instituição detentora da supramencionada licença.

Ao utilizador é apenas permitido o descarregamento para uso pessoal, pelo que o emprego do(s) título(s) descarregado(s) para outro fim, designadamente comercial, carece de autorização do respetivo autor ou editor da obra.

Na medida em que todas as obras da UC Digitalis se encontram protegidas pelo Código do Direito de Autor e Direitos Conexos e demais legislação aplicável, toda a cópia, parcial ou total, deste documento, nos casos em que é legalmente admitida, deverá conter ou fazer-se acompanhar por este aviso.

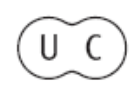




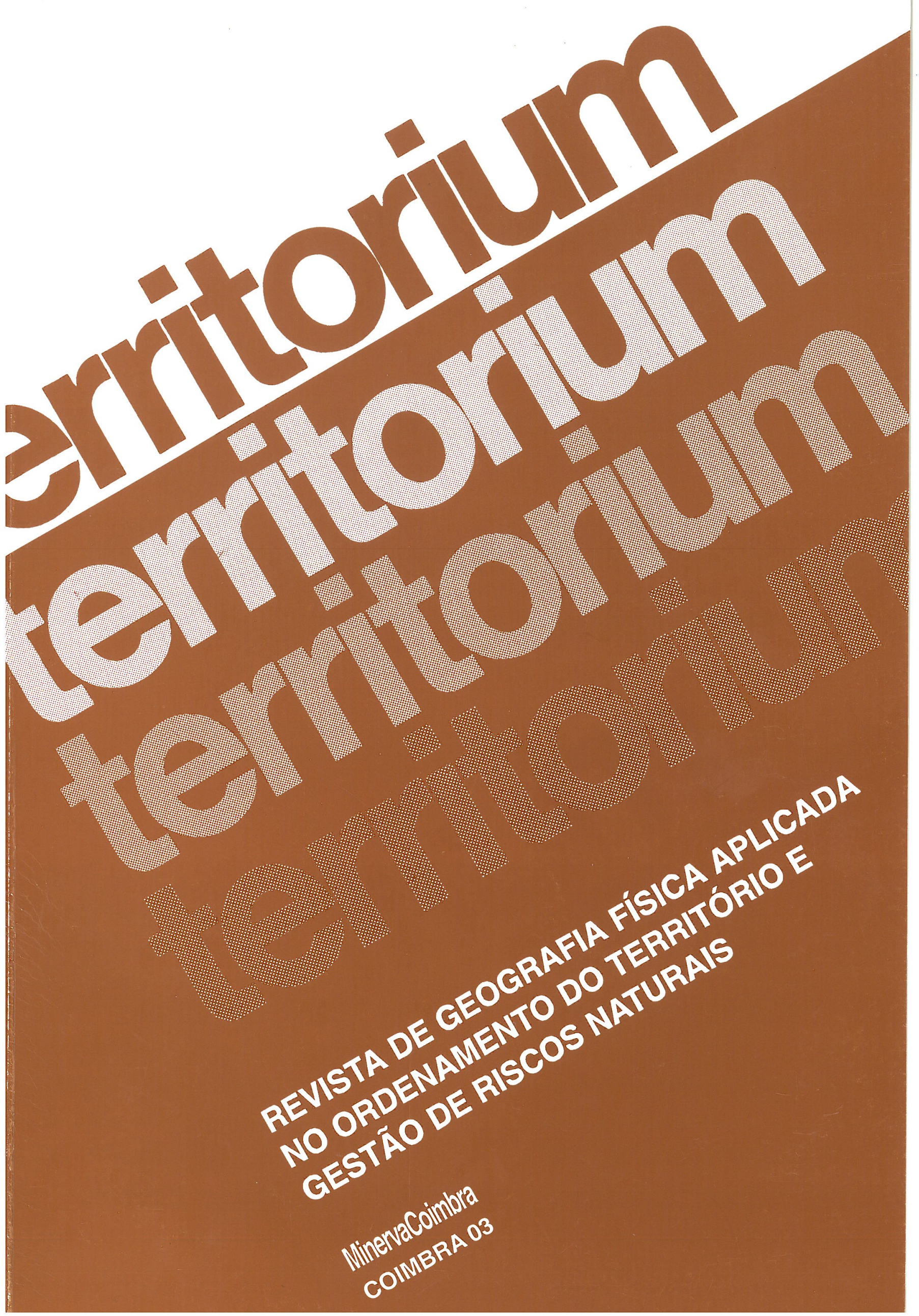




\title{
O litoral brasileiro: a valorização do espaço e os riscos socioambientais
}

\author{
Antonio Carlos Vitte*
}

\begin{abstract}
Resumo:
O litoral brasileiro está definido na Constituição Federal de 1988 como património natural. A sua extensão éde $7637 \mathrm{~km}$ de linha de costa, podendo alcançar 8500 se se considerarem as baías. A sua história morfogenética começa no período Cretácico, mas as diversidades e complexidades da linha de costa brasileira estão associadas também às mudanças climáticas do Quaternário. Os riscos socioambientais no litoral brasileiro estão associados ao processo de valorização capitalista do espaço, principalmente a partir de 1950 com a construção de instalações industriais e actualmente com a expansão de segundas residências, hoteis e complexos hoteleiros, além da exclusão social que obriga as famílias a construir as suas residências em áreas de risco, como os esteiros e os mangais.

Palavras chave:

Litoral, valorização do espaço, urbanizaçăo, exclusão social, riscos sócioambientais.
\end{abstract}

Résumé:

Le littoral brésilien est défini dans la Constitution Fédérale de 1988 comme patrimoine naturel. Sa longueur est de 7637 km de ligne de côte, pouvant atteindre les 8500 sel'on considère les baies. Son histoire morphogénétique commence au Crétacé, mais les diversités et les complexités de la ligne de côte brésiliènne sont aussi associées aux changements climatiques du Quaternaire. Les risques socioenvironnementaux dans le litoral brésilien sont associés aux procès de mise en valeur capitaliste de l'espace, principalement depuis 1950 avec la construction d'instalations industrielles et actuellement avec l'expansion de residences secondaires sur des aires de risque, comme vasières et mangroves.

Mots clés:

Littoral, mise en valeur de l'espace, urbanisation, exclusion sociale, risques socioenvironnementaux.

\section{Abstract:}

Brazilian coast is defined in the Federal Constitution of 1988 as natural heritage. It has $7637 \mathrm{~km}$ long, or 8500 if we consider its bays. Its morphogenetic history begins in the Cretacic period, but the diversity and the complexity of the coast line are also associeted to the climatic changes of the Quaternary. Socioenvironmental risks in the brazilian coast are associated to the processes of land capitalistic valorisation, mainly after 1950 with the construction of industrial plants and actually with the expansion of secondary residences on risk areas, as estuarine and mangrove areas.

Key words:

Coast, land valorization, urbanization, social exclusion, socioenvironmental risks.

\section{Introdução}

No Brasil, a zona costeira é definida no capítulo VI, artigo 255, da Constituição Federal, como um "Patrimônio Natural". O país possui 7.367 quilômetros de linha de costa, sem levar em conta os recortes como as baías, reentrâncias, etc. que ampliam significativamente essa extensão, elevando-a para mais de 8,5 mil quilômetros. Em sua maior porção, o litoral brasileiro está situado no Atlântico Sul, e pequena parcela (extremo norte do país) está situado no mar do Caribe: Quanto às latitudes, o litoral brasileiro vai de 4,3 graus norte até 33,4 graus sul. Localizado majoritariamente na zona intertropical (IBGE 1991).

* Professor. Departamento de Geografia, UNICAMP, Campinas (SP), Brasil. CP 6251. CEP 13087-970. E-mail: vitte@uol.com.br,
A zona costeira brasileira abriga um complexo mosaico de ecossistemas de relevância ambiental. Ao longo da costa alternam-se mangues, restingas, campos de dunas, estuários, recifes de corais e outros ambientes importantes do ponto de vista ambiental. É na zona costeira que se localizam as maiores manchas da Mata Atlântica com a sua maior contigüidade reservada às escarpas da Serra do Mar nos Estados do Rio de Janeiro, São Paulo e Paraná. Vale recordar que esta vegetação possui biodiversidade superior à floresta amazônica, no que diz respeito à variedade de espécies vegetais.

O processo de formação territorial do Brasil acabou-se privilegiando esta mesma zona costeira como centro de polarização da hirterlândia continental. Uma grande concentração populacional, sendo que a localização de metrópoles como São Paulo e Rio de 
Janeiro interfere na gestão do território brasileiro. Há a existência de uma densa rede de circulação e alguns dos mais importantes parques industriais brasileiros.

Por outro lado, os municípios litorâneos apresentam graves problemas à infra-estrutura básica, a questão sanitária, a violência, a exclusão social e os diversos problemas de moradias. Devido ao preço da terra, a população excluída, assim como a classe trabalhadora, tem que se sujeitar a morar nas encostas das escarpas, construir palafitas em manguezais ou desembocaduras deltaicas, fato que agrava ainda mais as condições de qualidade de vida e de qualidade ambiental, refletindo o padrão de exclusão social no Brasil.

A nossa proposta é apresentar um quadro do processo e dos resultados da ocupação e da formação territorial na zona costeira brasileira. Esta formação territorial obedece a uma lógica de valorização do espaço, na qual o litoral é tratado como um recurso ambiental, mas também como um território dotado de infra-estrutura para servir a uma dinâmica capitalista.

A nossa tese é que uma discussão sobre riscos naturais no litoral brasileiro não pode deixar de considerar a valorização do espaço e a arquitetura territorial que se forma a partir deste processo capitalista. Os riscos e processos que acontecem na zona costeira, devem ser antes discutidos sob uma ótica da produção e organização do espaço em umdado contexto histórico. Obviamente que não estamos aqui desprezando os aspectos físico-naturais, pois os mesmos têm a propriedade de qualificar o espaço natural, na medida que sua epiderme é o resultado de um arranjo complexo entre os vários atributos que participam da arquitetura do sistema ambiental, possuindo uma dinâmica temporal que remonta no mínimo, ao Quaternário.

Assim, os processos e as formas resultantes fazem parte do balanço ecodinâmico das paisagens (TRICART, 1972) que, no caso da zona costeira, é mais complexa que na hinterlândia continental, o que coloca a zona costeira como uma das mais frágeis e ao mesmo tempo necessárias para o país.

\section{Impactos e riscos ambientais}

Risco, segundo o Novo Dicionário Aurélio da Língua Portuguesa (1986), diz respeito a perigo ou possibilidade de perigo. Esta situação de perigo é construída principalmente pela sociedade em suas múltiplas faces, como a material e a cultural. É nessa construção cultural mediada tanto no plano do cotidiano quanto das grandes determinações, que uma sociedade específica constrói as suas representações e o modus operandi de materializá-la em um dado momento histórico.

Assim, as sociedades constroem as representações de si e de seu ambiente, tematizando de forma direta o espaço, tanto físico quanto humano, assim com a sua consciência social. Estas representações constituem o que MORAES (1988) chamou de ideologias geográficas, que alimentam as concepções e as políticas territoriais dos Estados, constituindo-se na substância das representações coletivas acerca dos lugares pelas sociedades.

É dentro deste quadro que compreendemos a formação do conceito de risco em sua mais variada acepção, como risco de erosão, risco de contaminação hídrica, risco tecnológico, etc.

Segundo CHRISTOFOLETTI (1999), é difícil distinguir entre riscos e impactos, sendo que o conceito de riscos caberia para casos específicos, enquanto que o termo ambiental seria mais genérico e estaria associado as mudanças, alterações, transformações que ocorrem no ambiente. Outros autores como PUGA (1982) tem preferido utilizar o termo azar ambiental, que define como: "todo evento imprevisto com efeitos negativos sobre as atividades humanas, aos quais o homem deve ajustar-se. São as restrições que os indivíduos encontram em seu meio ambiente e que demandam respostas visando minimizar seus efeitos negativos" (p. 87).

De uma maneira geral, as noções de impactos e azares ambientais referem-se a eventos e alterações que ocorrem concretamente no ambiente, em diferentes magnitudes, duração, extensão temporal e espacial.

A noção de riscos ambientais freqüentemente é confundida com a de impactos ambientais, mas referese muito mais às possibilidades de ocorrência dos eventos danosos ao ambiente. CHRISTOFOLETTI (1999) assinala que: "o reconhecimento das áreas de riscos geoambientais e o estudo sobre os azares naturais refletem os efeitos dos impactos ambientais e a avaliação da vulnerabilidade das organizações sócio-econômicas. Todavia as atividades humanas podem ocasionar conseqüências que intensifiquem a magnitude e a frequiência dos fenômenos naturais, numa cadeia retroalimentativa" (p. 428).

LEAL (1995, p. 99), trabalhando com o processo de degradação ambiental em micro-bacia hidrográfica submetida à forte processo de favelização, adotou a seguinte definição de risco: "fontes de perigo e dificuldades potenciais (desmoronamentos, como perdas e/ou destruição de bens e moradias, disseminação de doenças, etc.)".

Para BRÜSEKE (1997, p. 124-125), os riscos ambientais atingem cada vez mais grupos sociais, independentes da posição social dos mesmos, ou populações inteiras em qualquer lugar.

O adjetivo ambiental aqui utilizado procura abarcar tanto as situações de risco que ocorrem no ambiente em seu sentido mais amplo, natural e construído pelo homem. 
Por outro lado, não podemos negar que ao longo da história natural dos lugares os mesmos acumularam uma série de propriedades construídas a partir das características de integração da landschafthülle, ao longo do tempo. Este processo de integração definiu tanto as características e propriedades naturais de um lugar, assim como os seus limiares. A noção de limiar possui implicações práticas nas pesquisas ambientais, pois, além de auxiliar na compreensão da evolução do relevo, auxilia na previsão de futuras transformações nos processos responsáveis pela modelagem de uma paisagem.

A noção de riscoambiental, não pode ser dissociada da valorização capitalista do espaço, já que os lugares são refuncionalizados a partir das transformações do valor no e dos espaços.

\section{A macro-compartimentação dolitoral brasileiro}

A configuração atual do litoral brasileiro representa o resultado de longa interação entre os processos tectônicos, geomorfológicos, climáticos e oceanográficos. Uma das divisões mais aceitas do litoral brasileiro foi feita por SILVEIRA (1964), que identificou cinco grandes regiões geográficas: Norte, Nordeste. Leste ou Oriental, Sudeste e Sul, com cada região sendo subdividida em macrocompartimentos, conforme o quadro 1 , figura 1 .

\begin{tabular}{|c|c|c|}
\hline Região & Compartimento & \multirow{6}{*}{$\begin{array}{l}\text { Quadro } 1 \text { - Divisão Geomorfológica do } \\
\text { Litoral Brasileiro. } \\
\text { Fonte: SILVEIRA (1964); MÜLHE (1998). }\end{array}$} \\
\hline Norte & $\begin{array}{l}\text { Litoral do Amapá } \\
\text { Golfão Amazônico } \\
\text { Litoral de Reentrâncias Pará-Maranhão }\end{array}$ & \\
\hline Nordeste & $\begin{array}{l}\text { Costa Semi-Árida Norte } \\
\text { Costa Semi-Árida Sul } \\
\text { Costa dos Tabuleiros Norte } \\
\text { Costa dos Tabuleiros Centro } \\
\text { Costa dos Tabuleiros Sul } \\
\end{array}$ & \\
\hline Oriental & $\begin{array}{l}\text { Litoral de Estuários } \\
\text { Abrolhos } \\
\text { Embaiamento de Tubarão } \\
\text { Bacia de Campos } \\
\end{array}$ & \\
\hline Sudeste & $\begin{array}{l}\text { Litoral dos Cordões Litorâneos } \\
\text { Litoral das Escarpas Cristalinas do Norte } \\
\text { Litoral das Planicies Costeiras e Estuários } \\
\text { Escarpas Cristalinas do Sul } \\
\text { Litoral das Planícies Litorâneas de Santa Catarina }\end{array}$ & \\
\hline Sul & $\begin{array}{l}\text { Litoral Retificado do Norte } \\
\text { Litoral do Sistema Lagunar-Barreira do Rio Grande do Sul }\end{array}$ & \\
\hline
\end{tabular}

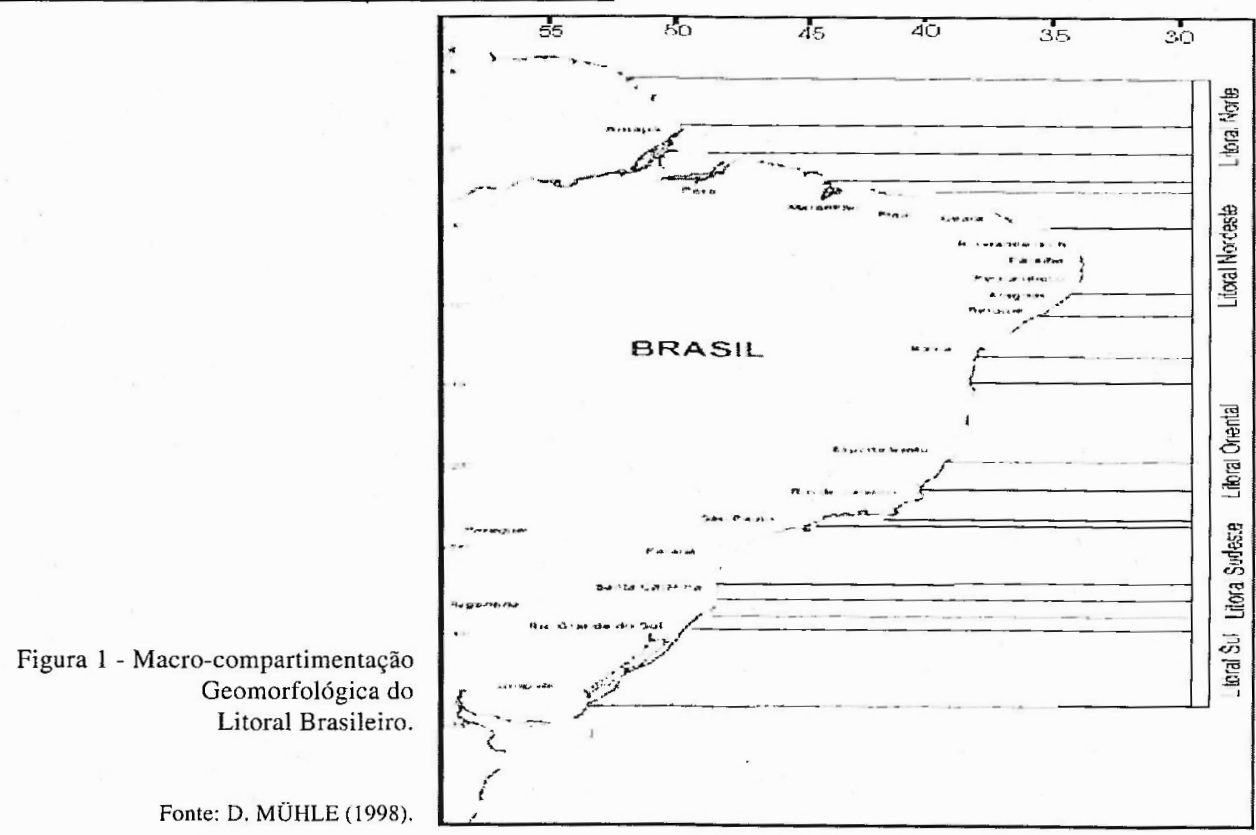




\section{A valorização do espaço}

Entendemos valorização como a mensuração qualitativa e quantitativa de um bem ou um conjunto de bens, onde o preço aparece como o ato de valorar. Por outro lado, valorizar significa a realização (objetivação) do valor, sua apropriação material. Éo ato de transformar materiais da natureza em valores de uso, dando-lhes uma utilidade para a vida humana. A valorização é, portanto, resultado do trabalho humano ao transformar recursos naturais em produtos e ao materializar-se em objetos criados. No mundo moderno, o processo de valorização implica no estabelecimento de fins e a avaliação de alternativas e meios.

O maior desafio atualmente é erigir bases de argumentação e análise sobre a valorização dos lugares e não simplesmente da natureza. Entendemos para efeito analítico, lugar, antes de tudo, como um meio natural, um substrato físico-biótico que aloca e sustenta grupos humanos. Esta premissa nos remete a refletirmos que cada lugar possui determinados estoques de variados produtos naturais e que o seu valor, advém não apenas do estoque dos recursos, mas também de sua situação locacional.

Para não cairmos na análise empirista, acreditamos que a noção de preço da terra venha a ser a melhor expressão fenomênica do valor do espaço. Desta forma, fugimos do perigo empirista de tomar o lugar como único e exclusivo.

Um dos indicadores mais objetivos para tal situação éas variações do mercado fundiário. Nele, a composição do preço da terra é dada pelas vantagens comparativas, os estoques de recursos existentes, o estado geral das condições existentes e os atrativos locacionais. Não podemos nos esquecer da ação do Estado que pela regulação, pelo planejamento e as políticas configura fatores que atuam na composição do preço da terra.

No caso da zona costeira brasileira, pode-se dizer que uma estrutura fundiária ocupa todo o litoral, em um processo de expansão fundiária que iniciou-se a partir das regiões metropolitanas, com conflitos de titularidade de propriedade da terra.

O Estado Nacional, por meio da administração pública, é o maior agente impactante na zona costeira, com a capacidade de reverter tendências de ocupação e gerar novas perspectivas de uso, sobretudo pela imobilização de áreas, mediante tombamentos, e pela instalação de grandes equipamentos ou dotação de infra-estruturas, como estradas, portos ou complexos industriais. Estas ações acabam sendo indutoras de fluxos migratórios e povoamento do litoral.

Assim, no caso brasileiro, a análise da ação do Estado por suas políticas acaba sendo importante no estudo da definição do valor de uma localidade.

\section{A zona costeira, os recursos ambientais e o lugar}

A definição de zona costeira é muito polêmica na literatura internacional. Em muitos casos não necessariamente a borda litorânea é apenas a borda marítima de compartimentos naturais. No caso brasileiro estas condições adentram de forma significativa em direção à hinterlândia continental. De uma maneira geral, poderíamos definir zona costeira como a zona de interação entre os meios terrestres, marinhos e atmosféricos.

Enquanto valor natural deve-se entender o litoral como um recurso que é depositário de produtos; ou seja, é a quantidade de materiais depositados na superfície terrestre que se apresentam nos fluxos econômicos como mercadorias, passíveis de ter seus preços médios aferidos no mercado. Os recursos ambientais referem-se a condições de vida e produção, circunscrevendo fatores de difícil contabilização, como a beleza cênica ou a originalidade paisagística, por exemplo.

Mas estes recursos, além das análises empreendidas pela economia, devem ser considerados sob uma perspectiva, tendo por referência a definição de lugares, e em destaque a consideração sobre a renda fundiária e a valorização do espaço.

O lugar, deve ser entendido como uma unidade de investigação e gestão, uma realidade material físico-biótica e social, cuja denominação obedece ao recorte pelo qual é analisada por seu investigador ou gestor. O lugar pode ser um ecossistema, uma biota, uma unidade geoambiental, um habitat, um município, uma planta produtiva. Mas antes de tudo, o lugar deve ser analisado como um espaço de produção e reprodução de um grupo humano, uma possibilidade de uso social com um dado potencial produtivo, o qual permite uma abordagem vocacional que desvendaria suas vantagens e desvantagens, em face de cada uso, em comparação a outros lugares.

O lugar pode ser tomado como uma riqueza natural, representada por uma dada quantidade de recursos naturais ali depositados e por um conjunto de características que podem ser agrupadas nos conceitos geográficos de posição e situação, em outros termos, pelos elementos que definem o que comumente é denominado de condições locais. Assim, o lugar qualifica-se economicamente pelos bens que abriga, mas também por sua localização e caracterização geral.

Os lugares apresentam um valor contido, o qual se manifesta concretamente envolto por algumas mediações básicas. A primeira é o caráter histórico, ou seja, a história das técnicas que irá qualificar a matéria telúrica como recurso natural. Assim como o contexto histórico potencializa a valorização substantiva do lugar. Uma outra mediação é a relatividade social da valorização, que em outras 
palavras, é a geratriz do grau de atratividade social de um lugar.

É a partir da relação dialética destas mediações que se tem o valor criado, que advém da forma como se dá a exploração das condições locais, variando conforme a atividade desenvolvida.

É dentro deste quadro de valorização do espaço que o litoral pode ser tomado. Nele ocorre uma situação diferenciada em relação à hinterlândia, pois apresenta características naturais e de ocupação diferenciadas, o que o circunscreve em um rol restrito de determinadas atividades. Um dos grandes qualificativos é o seu contato direto com o mar, propiciando atividades de exploração dos recursos marinhos. Uma situação privilegiada pois o mar é simplesmente a maior reserva de recursos do planeta.

Ademais, o litoral permite a realização da circulação, pois detém a primazia dos pontos terminais dos fluxos intercontinentais de mercadorias, ainda hoje majoritariamente executados pelo transporte marítimo. A navegação é, assim, um elemento importante de qualificação dos sítios litorâneos, sendo que o litoral detém um quase monopólio das atividades portuárias do mundo. E por fim, vale frisar que o litoral particulariza-se pela apropriação cultural que o identifica como um espaço de lazer, por excelência, lembrando que os espaços preservados são os mais valorizados atualmente.

Outra característica do contexto atual, é que cerca de dois terços da humanidade habitam em zonas costeiras. É na beira-mar que estão localizadas a maior parte das metrópoles contemporâneas. Os litorais, portanto, abrigam um contingente populacional denso e concentrado, ao qual corresponde uma concentração das atividades, localizando-se também à beira-mar, boa parte das instalações industriais.

Assim, os litorais apresentam uma localização diferenciada e passível de imprimir especificidades nas formas de ocupação e uso do solo nele praticados. Em suma, os litorais sãoáreas potencialmente geradoras de renda diferencial. Tal forma de renda fundiária advém das qualidades relativamente raras dos recursos naturais e ambientais presentes em uma dada localidade. E as zonas costeiras caracterizam-se por serem típicos espaços com vantagens locacionais, um espaço finito e relativamente escasso, o que faz com que o seu valor seja mais elevado do que na hinterlândia, condicionando um direcionamento dos usos.

\section{O padrão de ocupação da zona costeira no Brasil}

O padrão de ocupação colonial do território brasileiro configurou-se na costa litorânea. Os primeiros núcleos de povoamento constituíram-se em centros de difusão e centralização territorial. O padrão espacial foi o de bacias de drenagem, sendo os espaços portuários os nós entre e hinterlândia continental e as rotas da economia-mundo.

Vale lembrar que no sáculo XVI, dos 18 núcleos pioneiros, apenas São Paulo não estava localizado na zona costeira, ainda que cerca de $80 \mathrm{~km}$ de distância do litoral. Em sua grande maioria, os portos estavam situados em zonas estuarinas e permitiram o desenvolvimento de redes de circulação fluvial ou terrestre, sempre no sentido leste-oeste. As primeiras redes de cidades surgiram nos entroncamentos destas redes e tinham a funçãode entreposto comercial, cujos produtos eram drenados pelos portos.

As principais áreas de polarização do litoral brasileiro, no período colonial, eram as seguintes:

a) Litoral Oriental da Zona da Mata Nordestina: área polarizada por Olinda/Recife. Zona produtora de açúcar, com complementariedades na hinterlândia com a pecuária e agricultura de abastecimento.

b) Recôncavo Baiano: área polarizada pela cidade de Salvador, sede do governo-geral. Foi a maior cidade brasileira até o final do século XVIII, ponto das rotas internacionais, articuladora de circuitos internos da produção pecuária, agrícola e mineral.

c) Litoral Fluminense: área polarizada pela cidade do Rio de Janeiro, que conhece grande crescimento ao abrigar a corte real portuguesa no início do século XIX. Zona de produção e abastecimento para as áreas mineradoras e de embarque de produtos minerais, destacando-se a agricultura canavieira.

d) Litoral Paulista: polarizada por Santos e São Vicente, articulava o litoral com o Planalto Paulistano. Oseu principal papel foi justamente ser área de circulação, cercado por um rosário de núcleos urbanos.

Além destas zonas de adensamento, deve-se destacar também a existência de portos isolados como os de Belém, São Luiz, Fortaleza e Natal que drenavam o seu entorno imediatoe estavam completamente isolados dos demais arquipélagos populacionais.

Em alguns destes arquipélagos, as redes de infraestrutura foram modernizadas, com a construção de ferrovias que drenavam as mercadorias mais rapidamente para os portos e dotava a zona costeira de maiores vantagens locacionais. Esta situação não foi válida apenas para a localização industrial que, por demandar matéria-prima e energia, preferia instalarse no interior continental, incentivando o desenvolvimento da rede urbana para o interior do Brasil.

Já no século XX, mas propriamente a partir da década de 1950 , ocorreu uma mudança no ritmo de 
ocupação da costa em face ao padrắo de acumulação e a consolidação do padrão urbano-industrial. Foi aquele momento em que as corporações transnacionais instalaram-se no Brasil. As corporações apresentavam uma forte dependência de abastecimento de insumos externos. Tal dependência condicionou a localização industrial nas proximidades dos sítios portuários. Instalaram-se na zona costeira diversas indústrias ligadas ao processamento mineral, beneficiamento da soja e da celulose. E a instalação de vários desses ramos numa mesma localidade resultou em complexos industriais, como os de Cubatão (SP) e de Camaçari (BA).

Em 1950, a atividade industrial era responsável por $24 \%$ do Produto Interno Bruto (PIB). Tal percentual se elevou para mais de $40 \%$ em 1980 . Esta evolução demonstra que a indústria não pode ser desprezada na avaliação dos vetores de ocupação da costa brasileira e em seu papel na dinamização dos centros urbanos e do setor de comércio e serviços.

Um outro vetor de análise é o da segunda residência, altamente disseminado no espaço litorâneo brasileiro, principalmente no entorno das grandes capitais regionais. Esta formação é responsável pelo processo de especulação imobiliária e do dinamismo da construção civil ao longo da costa brasileira que, a despeito das crises econômicas, se consubstanciaram em mercados altamente rentáveis.

Em termos ambientais, o caráter impactante da segunda residência está diretamente relacionado à capacidade dos poderes públicos em ordenar o uso do solo. A segunda residência vai constituir um novo padrão do fluxo migratório no litoral brasileiro, que muitas vezes desorganiza a sociabilidade do lugar.

Um outro processo social que teve forte impacto no litoral foi a urbanização pós-década de 1950 que impulsionou forte contingente migratório em direção à costa, particularmente naquelas dotadas de parque industrial.

Como nem toda população foi absorvida pelo setor industrial ou pelo setor terciário, houve a constituição de um segmento marginal que exerceu forte pressão social no aumento da demanda de serviços urbanos, em um quadro de carência social e estrutural. Um dos maiores problemas resultantes éo saneamento básico; outro é o processo de favelização, pois com o preço da terra muito elevado, a população marginalizada acabou por ocupar os morros ou áreas insalubres nas zonas dos manguezais.

Juntos, a segunda residência e a favelização constituem em marco na paisagem da zona costeira brasileira que, a partir da década de 1970, teve muitas das cidades portuárias constituindo-se em metrópoles costeiras.

A atividade turística também vem se constituindo em um importante vetor nas últimas décadas, cuja ação incide tanto nas aglomerações litorâneas quanto nas áreas de baixa ocupação na costa. Vários processos estão associados a esta atividade que pode alterar o espaço intra-urbano de uma cidade litorânea, principalmente quando está articulada a espaços de segunda residência, 'geralmente de alto padrão. $\mathrm{O}$ turismo também pode ser uma atividade indutora da ocupação de novas áreas, sendo que o crescimento do setor vem sendo alimentado pelo crescimento do padrão de renda das classes médias e altas e pela demanda estrangeira.

Atualmente a atividade turística é o setor produtivo que mais cresce na zona costeira, fato que vem exigindo do Estado e da iniciativa privada a melhoria da infra-estrutura das cidades situadas na zona costeira.

\section{Os riscos socioambientais no litoral brasileiro.}

- As aglomerações urbanas e os distritos industriais são responsáveis por forte poluição química e orgânica de praias e lagunas. Na região norte do país, os parques industriais ainda não são tão densos como no sudeste, mas os igarapés e zonas de manguezais estão sendo ocupados por palafitas, sem nenhum acesso às condições sanitárias.

- No nordeste, de Paraíba até Alagoas as pequenas drenagens, chamadas de rios do açúcar, apresentam altas cargas poluidoras. De outro lado, os interesses de agroindústrias do açúcar, corporações industriais e empresários do turismo ocupam e constroem uma densa rede de circulação nos tabuleiros costeiros, intensificando os processos erosivos nas falésias.

- Estuários, baías e lagunas costeiras têm sofrido grandes contaminações químicas e orgânicas (Guanabara (RJ), Santos (SP), Todos os Santos (BA), Vitória (ES), estuário de Guaíba (RS), Paranaguá (PR), Florianópolis (SC)).

Causas:Ocupação destas áreas por parte da população mais carente (palafitas). A poluição é feita por dejetos humanos, por águas servidas e por fortes cargas de resíduos químicos e metais pesados, emitidas por indústrias poluidoras.

- A especulação imobiliária provoca escassez de terras que leva à ocupação dos manguezais com aterros, linhas de praia formadas por cordões arenosos, campos de dunas. $O$ poder público, por sua vez, atua com obras de infra-estrutura urbana, como os calçadões, asfaltamentos ou mesmo a retilinização de pequenos canais flúvio-marinhos.

- A especulação imobiliária e empresas de mineração atuam no desmonte e abertura de 
cavas nos maciços costeiros e insulantes, como em Santos-São Vicente (SP), Niterói-Rio de Janeiro (RJ), Florianópolis, Porto Alegre.

- A população mais carente, em função do preço da terra, acaba ocupando caoticamente as encostas dos morros. As intervenções urbanas, associadas à localização das pedreiras tem preparado o terreno (morros) para catástrofes urbanas lamentáveis, com escorregamentos.

- Outra situação ambiental, mas nonível sistêmico da paisagem, é a poluição urbano-industrial, onde Cubatão (SP) foi o paradigma exemplar, com a geração de ilhas de calor, fenecimento da Mata Atlântica situada nas escarpas da Serra do Mar devido à precipitação ácida, maciços processos de escorregamento.

De uma maneira geral, a degradação da natureza vem se fazendo de uma forma mais agressiva nas proximidades das áreas mais urbanizadas e industrializadas da costa brasileira. Que também estão associadas à forte especulação imobiliária, A grosso modo coincidem com as maiores aglomerações populacionais litorâneas do país. As localidades são as seguintes: Região metropolitana de Belém (PA), Ilha de São Luiz (MA), Região metropolitana de Fortaleza (CE), municípios de Macau e Natal (RN), João Pessoa (PB), Região metropolitana de Recife (PE), Maceió (AL), foz do rio São Francisco (AL/SE), Aracaju (SE), Região metropolitana de Salvador(BA), Vitória (ES), Anchieta (SE), municípios de Campos e Macaé (RJ), Região metropolitana do Rio de Janeiro, Região metropolitana da Baixada Santista (SP), Paranaguá (PR), Itajaí (SC), município de Rio Grande (RS).

Destas dezenove localidades, dezesseis localizam-se em estuários e baías, doze alocam atividades portuárias de grande porte, onze abrigam capitais dos respectivos estados.

\section{Referências bibliográficas}

AB'SABER, Aziz N. (2000) - A Identificação de Áreas Críticas no Litoral Brasileiro.O Litoral do Brasil. São Paulo, Metalivros.

BRUSEKE, F. J. (1997) - «Risco Social, Risco Ambiental, Risco Individual ». Ambiente \& Sociedade, Campinas, UNICAMP, ano $1, n^{\circ} 1$.
CHRISTOFOLETTI, Antonio (1999) - Modelagem de Sistemas Ambientais. São Paulo: Edgard Blucher.

LEAL, Antonio Cezar (1995) - Urbanização e Meio Ambiente na Microbacia do Areia Branca- Campinas. Dissertação de Mestrado, IGCE-UNESP-Rio Claro.

MORAES, Antonio Carlos Robert de (1988)-Ideologias Geográficas. Espaço, Cultura e Políticano Brasil. São Paulo: HUCITEC.

MORAES, Antonio Carlos Robert de (1994) - « Fixaçăo do valor e capital fixo ». Boletim Paulista de Geografia, 72, São Paulo, AGB.

MORAES, António Carlos Robert de (1999) - Contribuições para a Gestão da Zona Costeira do Brasil. Elementos para uma geografia do Litoral Brasileiro. São Paulo: HUCITEC/EDUSP.

MORAES, Antonio Carlos Robert de (2000) - Bases da Formação Territorial do Brasil. O território colonial no longo século XVI. São Paulo, HUCITEC.

MORAES, Antonio Carlos Robert de (2001) - Geografia, Capitalismo e Meio Ambiente. São Paulo, FFLCH, USP, Tesé de Livre-Docência.

MORAES, Antonio Carlos Robert de (2002) - Território e História no Brasil. São Paulo: Annablume/HUCITEC.

MORAES, Antonio C. R. \& COSTA, Wanderley Messias da (1984) - Geografia Crítica: a valorização do espaço. São Paulo. HUCITEC.

MÜHLE, Dieter (1998) - «O Litoral Brasileiro e sua Macro-Compartimentação». In: GUERRA, Antonio José Texeira. \& CUNHA, Sandra Batista da. Geomorfologia do Brasil. Rio de Janeiro: Bertrand Brasil.

PUGA, D. (1982) - Controle de Plantas Daninhas no Algodão: um estudo de percepção do meio-ambiente. Dissertação de Mestrado, IGCE-UNESP- Rio Claro.

SCIENTIFIC AMERICAN BRASIL, ano 1, $\mathrm{n}^{\circ} 12$, maio de 2003.

SILVEIRA, João Dias da (1964) - "O Litoral Brasileiro». In AZEVEDO, Aroldo de. (org.). Brasil: A Terra e o Homem. Vol II, São Paulo, Cia Editora Nacional.

TRICART, Jean (1972). Ecodinâmica. Rio de Janeiro, IBGE.

www.ibge.gov.br/censos 
